\title{
Dyslipidemia and Conventional Risk Factors in Patients with Acute Coronary Syndrome Admitted in a CCU of a Tertiary Care Hospital of Bangladesh
}

\author{
Md Mahfuzur Rahman ${ }^{1}$, Farid Uddin Ahmed ${ }^{2}$, Sanjida Sharmin ${ }^{3}$, Tanvir Hyder ${ }^{4}$, Saifuddin Nehal ${ }^{5}$ \\ ${ }^{1}$ Department of Cardiology, Abdul Malek Ukil Medical College, Noakhali, ${ }^{2}$ Department of Community \\ Medicine, Rangamati Medical College, Rangamati, ${ }^{3}$ Department of Obstetrics and Gynaecology, \\ Chittagong Medical College \& Hospital, Chittagong, ${ }^{4} 250$ Bed General Hospital, Noakhali, ${ }^{5}$ Niramoy \\ Hospital Ltd, Noakhali
}

\begin{abstract}
Key words:

Acute coronary

syndrome,

Dyslipidemia, Conventional risk factors.

Background: Coronary artery disease (CAD) is the single largest cause of death in the developed countries and is one of the leading causes of disease burden in developing countries. The prevalence of dyslipidemia and conventional risk factors profile at the time of admission in patients with Acute Coronary Syndrome (ACS) is not well described in our context. The aim of this study was to investigate the prevalence of dyslipidemia and conventional risk factors profiles of patients with ACS in a tertiary care center of Bangladesh.

Methods: This descriptive cross-sectional study included 96 admitted patients of ACS [30 cases of Unstable Angina, 25 cases of Non ST segment Elevation Myocardial Infarction and 41 cases of ST segment Elevation Myocardial Infarction] from the Department of Cardiology, Abdul Malek Ukil Medical College Hospital, Noakhali, Bangladesh from January 2019 to June 2019. Fasting serum lipid profile was obtained within 24 hours of hospitalization and demographic and other cardiovascular risk factors were documented.

Results: The mean age of the subjects were $57.7 \pm 14.4$ years with majority (71.9\%) being male. The most frequent reported risk factor was smoking, present in $55.2 \%$ of patients, followed by hypertension (47.9\%), diabetes (37.5\%), dyslipidemia (27.1\%) and family history of CAD (15.6\%). Based on Body Mass index $50 \%$ patients were obese $\left(\geq 25 \mathrm{~kg} / \mathrm{m}^{2}\right)$ and $69.8 \%$ had central obesity based on waist circumference. The lipid profile analysis revealed that $99 \%$ of patients had some type of dyslipidemia, and the most frequent was high level of triglyceride and low levels of high-density lipoprotein cholesterol ( $68.8 \%$ of cases in each).

Conclusion: Dyslipidemia is a significant risk factor in patients with ACS and high TG and low $H D L-C$ were more prevalent. Careful attention to its management may help to reduce further events.
\end{abstract}

(Cardiovasc j 2021; 14(1): 24-29)

\section{Introduction:}

Coronary artery disease (CAD) accounting for more than 9 million deaths in 2016 according to the World Health Organization estimates and threefourths of this global deaths occurred in the low and middle-income countries. ${ }^{1}$ Recent studies from Bangladesh observed that prevalence of cardiovascular diseases, especially CAD is high along with an upward trend and its associated risk factors are on the rise too in Bangladeshi adults. ${ }^{2,3}$ Therefore, immediate public health intervention is warranted to address the issue so that a further increase can be alleviated and the morbidity and mortality associated with it can be reduced.

Traditionally there are some conventional risk factors for $\mathrm{CAD}$ e.g. increasing age, male sex,

Address of Correspondence: Dr. MD. Mahfuzur Rahman, Department of Cardiology, Abdul Malek Ukil Medical College \& Hospital, Noakhali, Bangladesh. Email: msbrana73@gmail.com

- 2020 authors; licensed and published by International Society of Cardiovascular Ultrasound, Bangladesh Chapter and Bangladesh Society of Geriatric Cardiology. This is an Open Access article distributed under the terms of the CC BY NC 4.0 (https://creativecommons.org/licenses/by-nc/4.0) 
positive family history, hypertension, smoking, obesity, dyslipidemia, metabolic syndrome, diabetes, lack of exercise and some emerging risk factors, e.g. C-reactive protein, Fibrinogen, Homocysteine etc. ${ }^{4}$ However, certain risk factors may predominate in certain regions. Dyslipidemia with an increase in total cholesterol (TC), lowdensity lipoprotein cholesterol (LDL-C), triglycerides (TG) and decrease in high-density lipoprotein cholesterol (HDL-C) is one of the major risk factors for the ACS and alone account for more than $50 \%$ of population attributable risk. ${ }^{5,6}$ Untreated dyslipidemia is the strongest predictor of in-hospital death. ${ }^{7}$

Dyslipidemia is an independent and modifiable risk factor that is common in our population. ${ }^{8}$ It remains unrecognized until detected during the first presentation with ACS. So, this study aimed to find out the prevalence of dyslipidemia within 24 hours of admission with ACS and thereby help to the early classification of dyslipidemia and select the appropriate therapy. The prevalence of other conventional risk factors of CAD was also evaluated in the study.

\section{Methods:}

This descriptive cross sectional study was conducted among 96 patients with a diagnosis of ACS admitted at Abdul Malek Ukil Medical College Hospital, Noakhali, Bangladesh from January 2019 to June 2019 after taking Ethical clearance from the institutional Ethical Review Committee.

All the participants had signed the consent for the study. History and clinical examination were performed as per the pre-structured proforma. All cases above the age of 18 years with a diagnosis of ACS were enrolled by a convenience sampling method. Patients with stable CAD were excluded. The sample size of 96 was calculated based on the $63 \%$ prevalence of dyslipidemia in patients with ACS in the study conducted at another tertiary care hospital in Bangladesh with 15\% permissible error. $^{8}$

Demographic features (age, gender) and cardiovascular risk factors [smoking: current or former, family history of CAD (first degree relatives such as siblings and parents usually aged $<50$ years \{females\} or $<55$ years \{males\}), hypertension: under medication, diabetes: random blood glucose $\geq 200 \mathrm{mg} / \mathrm{dl}$ and/or under medication, reported dyslipidemia (under medication)] related data were recoded.

An electrocardiogram (ECG) at presentation was performed in all the patients and the cases were categorized as unstable angina (UA), non-ST elevation MI (NSTEMI) and ST-elevation MI (STEMI) based on the history, ECG changes and cardiac markers. ${ }^{9}$ Fasting serum lipid profile was obtained within 24 hours of hospitalization. Lipid assay was done with Enzymatic Colorimetric Test for TC and TG with lipid Clearing Factor. LDL-C was determined by direct method and HDL-C by precipitation method.

Dyslipidemia was defined based on NCEP ATP III criteria i.e., any of the following fasting lipid profile values obtained within 24 hours of the event: TC $\geq 200 \mathrm{mg} / \mathrm{dl}, \mathrm{TG} \geq 150 \mathrm{mg} / \mathrm{dl}, \mathrm{LDL} \geq 130 \mathrm{mg} / \mathrm{dl}$, and $\mathrm{HDL} \leq 40 \mathrm{mg} / \mathrm{dl}$ for male and $\leq 50 \mathrm{mg} / \mathrm{dl}$ for female or patient already on medication for dyslipidemia. ${ }^{10}$ Dyslipidemia was evaluated with age, sex, and other risk factors.

Statistical analyses were performed by SPSS version 23. Both descriptive and inferential data analysis methods were used. Descriptive methods included frequency tables, bar charts and summary statistics (means \pm standard deviations and frequency and percentage). Inferential methods included chi-square tests of association, student's $t$ test and One Way Analysis of Variance (ANOVA) test. $\mathrm{p}<0.05$ was considered as statistical significance.

\section{Results:}

Out of 96 ACS patients there were 30 cases of UA, 25 cases of NSTEMI and 41 cases of STEMI. Age ranges from 21-95 years with mean age of $57.7 \pm 14.4$ years. Majority of the patients were male (71.9\%) with a male to female ratio of 2.55:1. Most prevalent risk factor was smoking $(55.2 \%)$, followed by hypertension (47.9\%), diabetes mellitus (37.5\%), reported dyslipidemia (27.1\%) and family history of IHD (15.6\%). Prevalence of smoking and family history of CAD was significantly higher and prevalence of hypertension and reported dyslipidemia was significantly lower in male compared to female. Prevalence of obesity and central obesity was also higher among male patients compared to female (Table I). 
Table-I

Pattern of different risk factors in ACS patients stratified by gender.

\begin{tabular}{lcccc}
\hline Variables & Total $(\mathrm{n}=96)$ & Male $(\mathrm{n}=69)$ & Female $(\mathrm{n}=27)$ & $\mathrm{p}$ value \\
\hline Age, years & $57.69 \pm 14.36$ & $56.38 \pm 13.79$ & $61.04 \pm 15.52$ & $0.154^{\dagger}$ \\
Smoking & $53(55.2)$ & $52(75.4)$ & $1(3.7)$ & $<0.001^{*}$ \\
Hypertension & $46(47.9)$ & $28(40.6)$ & $18(66.7)$ & $0.021^{*}$ \\
F/H of CAD & $15(15.6)$ & $15(21.7)$ & $0(0)$ & $0.008^{*}$ \\
Diabetes & $36(37.5)$ & $25(36.2)$ & $11(40.7)$ & $0.682^{*}$ \\
Dyslipidemia & $26(27.1)$ & $13(18.8)$ & $13(48.1)$ & $0.004^{*}$ \\
BMI, e"25 kg/m & $48(50.0)$ & $34(49.3)$ & $9(33.3)$ & $0.537^{*}$ \\
Central obesity & $67(69.8)$ & $53(76.8)$ & $14(51.9)$ & $0.017^{*}$ \\
\hline
\end{tabular}

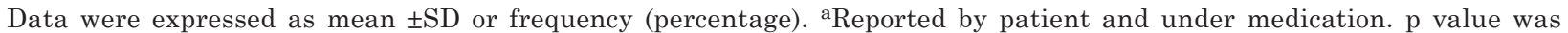
obtained from †Independent sample t test or ${ }^{*}$ Chi-square test.

The mean TC, TG, LDL-C and HDL-C among the participants were $196.94 \pm 49.32 \mathrm{mg} / \mathrm{dl}$, $201.20 \pm 82.31 \mathrm{mg} / \mathrm{dl}, 120.10 \pm 37.01 \mathrm{mg} / \mathrm{dl}$ and $39.53 \pm 7.13 \mathrm{mg} / \mathrm{dl}$ respectively. Similarly, it was calculated for both males and females separately (Table II). The high serum level of TC was found in $36(37.5 \%)$, high serum level of TGs in $66(68.8 \%)$, high serum level of LDL-C in 35 (36.5\%) and low serum level of HDL-C in 66 (68.8\%) patients. Lipid profile was similar in both male and female patients except a higher prevalence of low HDL in female compared to their counterpart.

Majority of the patients $(40 / 96 ; 41.7 \%)$ had abnormalities in two lipid sub fractions, followed by $25(26 \%)$ with abnormality in one sub-fractions, $22(22.9 \%)$ in three sub-fractions and $8(8.3 \%)$ in all of the four sub-fractions. Only one patient had normal level in all of the four lipid sub fractions.
Figure 1 shows that, clustering of all four lipid abnormality was more prominent in female patients compared to male.

Patients admitted with STEMI was significantly younger than from the patients admitted with UA. Prevalence of hypertension and dyslipidemia was significantly higher in patients with UA compared to the patients admitted with NSTEMI/STEMI. Mean lipid profile values were comparatively higher in patients with NSTEMI and STEMI than patients admitted with UA. However, the differences failed to reach statistical significance. High TC level was observed comparatively more in patients with NSTEMI/STEMI compared to patients with UA without any statistical significance. In terms of TG, high level was observed significantly more in patients with NSTEMI compared to patients with STEMI and UA (Table III).

\section{Table-II}

Pattern of lipid profile in ACS patients stratified by gender

\begin{tabular}{lcccc}
\hline Lipid fractions & Total $(\mathrm{n}=96)$ & Male $(\mathrm{n}=69)$ & Female $(\mathrm{n}=27)$ & p value \\
\hline TC, mg/dl & $196.94 \pm 49.32$ & $199.06 \pm 52.69$ & $191.52 \pm 39.82$ & $0.504^{\dagger}$ \\
TG, mg/dl & $201.20 \pm 82.31$ & $205.97 \pm 91.20$ & $189.00 \pm 52.79$ & $0.367^{\dagger}$ \\
LDL, mg/dl & $120.10 \pm 37.01$ & $119.88 \pm 37.42$ & $120.67 \pm 36.61$ & $0.926^{\dagger}$ \\
HDL, mg/dl & $39.53 \pm 7.13$ & $39.84 \pm 7.89$ & $38.74 \pm 4.65$ & $0.500^{\dagger}$ \\
TC/HDL & $5.03 \pm 1.08$ & $5.05 \pm 1.12$ & $4.98 \pm 0.95$ & $0.726^{\dagger}$ \\
TG/HDL & $5.09 \pm 1.80$ & $5.16 \pm 1.94$ & $4.92 \pm 1.38$ & $0.554^{\dagger}$ \\
TC $(>200 \mathrm{mg} / \mathrm{dl})$ & $36(37.5)$ & $27(39.1)$ & $9(33.3)$ & $0.598^{*}$ \\
TG $(>150 \mathrm{mg} / \mathrm{dl})$ & $66(68.8)$ & $45(65.2)$ & $21(77.8)$ & $0.233^{*}$ \\
LDL $(>130 \mathrm{mg} / \mathrm{dl})$ & $35(36.5)$ & $23(33.3)$ & $12(44.4)$ & $0.309^{*}$ \\
Low HDL & $66(68.8)$ & $39(56.5)$ & $27(100.0)$ & $<0.001^{*}$ \\
\hline
\end{tabular}

Data were expressed as mean $\pm \mathrm{SD}$ or frequency (percentage); $\mathrm{P}$ value was obtained from †independent sample $\mathrm{t}$ test or ${ }^{*} \mathrm{Chi}$ square test. . ${ }_{<}<0 \mathrm{mg} / \mathrm{dl}$ for men and $<50 \mathrm{mg} / \mathrm{dl}$ for women. 
Table-III

Distribution of the risk factors and lipid profile in ACS patients stratified by ACS type $(n=96)$.

\begin{tabular}{lcccc}
\hline Variables & UA(n=30) & NSTEMI $(\mathrm{n}=25)$ & STEMI $(\mathrm{n}=41)$ & $\mathrm{p}$ value \\
\hline Age, years & $63.8 \pm 14.7$ & $57.7 \pm 11.9$ & $53.2 \pm 14.4$ & $0.008^{*}$ \\
Male sex & $17(56.7)$ & $20(80.0)$ & $32(78.0)$ & $0.081^{\dagger}$ \\
Smoking & $12(40.0)$ & $15(60.0)$ & $26(63.4)$ & $0.125^{\dagger}$ \\
Hypertension & $22(73.3)$ & $12(48.0)$ & $12(29.3)$ & $0.001^{\dagger}$ \\
F/H of CAD & $2(6.7)$ & $4(16.0)$ & $9(22.0)$ & $0.215^{\dagger}$ \\
Diabetes & $12(40.0)$ & $8(32.0)$ & $16(39.0)$ & $0.801^{\dagger}$ \\
Dyslipidemia & $17(56.7)$ & $4(16.0)$ & $5(12.2)$ & $0.001^{\dagger}$ \\
BMI, kg/m & $26.1 \pm 2.7$ & $24.1 \pm 2.8$ & $24.8 \pm 2.8$ & $0.027^{*}$ \\
TC, mg/dl & $183.63 \pm 51.71$ & $201.48 \pm 44.56$ & $203.90 \pm 49.53$ & $0.202^{*}$ \\
TG, mg/dl & $185.30 \pm 94.90$ & $221.96 \pm 73.74$ & $200.17 \pm 76.42$ & $0.260^{*}$ \\
LDL, mg/dl & $110.37 \pm 40.47$ & $119.28 \pm 28.24$ & $127.73 \pm 38.10$ & $0.147^{*}$ \\
HDL, mg/dl & $38.03 \pm 7.57$ & $38.64 \pm 6.87$ & $41.17 \pm 6.78$ & $0.144^{*}$ \\
TC/HDL & $4.91 \pm 1.24$ & $5.21 \pm 0.59$ & $5.02 \pm 1.78$ & $0.578^{*}$ \\
TG/HDL & $4.86 \pm 2.02$ & $5.74 \pm 1.61$ & $4.88 \pm 1.67$ & $0.118^{*}$ \\
TC $(>200 \mathrm{mg} / \mathrm{dl})$ & $8(26.7)$ & $10(40.0)$ & $18(43.9)$ & $0.219^{\dagger}$ \\
TG $(>150 \mathrm{mg} / \mathrm{dl})$ & $17(56.7)$ & $22(88.0)$ & $27(65.9)$ & $0.039^{\dagger}$ \\
LDL $(>130 \mathrm{mg} / \mathrm{dl})$ & $10(33.3)$ & $7(28.0)$ & $18(43.9)$ & $0.391^{\dagger}$ \\
Low HDL & $24(80.0)$ & $19(76.0)$ & $23(56.1)$ & $0.066^{\dagger}$ \\
\hline
\end{tabular}

Data were expressed as mean \pm SD or frequency (percentage), a On treatment; ${ }^{\dagger} p$ value was obtained from Chi-square test or *ANOVA test. ${ }^{\star}<40 \mathrm{mg} / \mathrm{dl}$ for men and $<50 \mathrm{mg} / \mathrm{dl}$ for women.

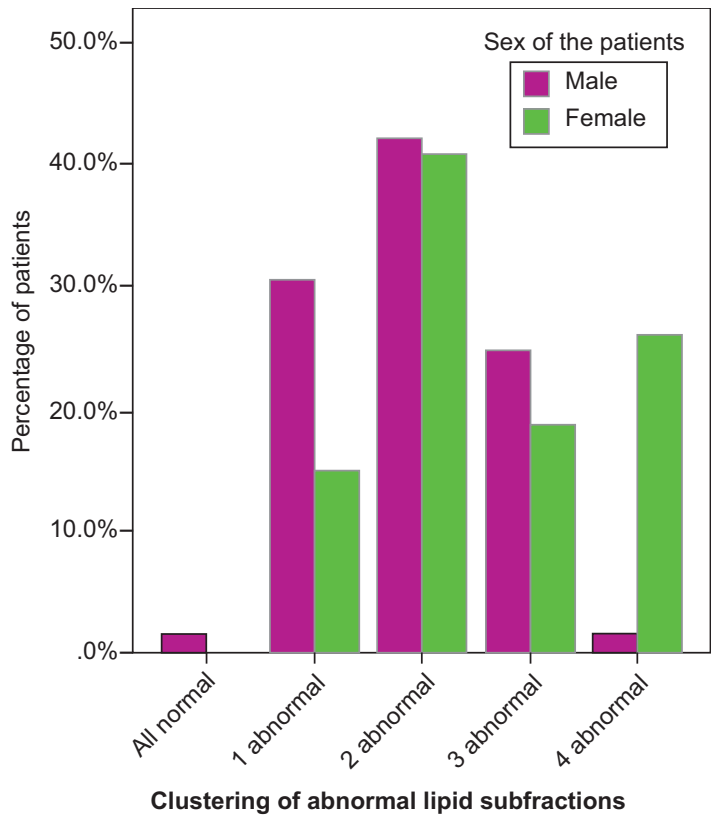

Fig.-1: Clustering of lipid sub-fractions abnormality between male and female patients with ACS.

\section{Discussion:}

This study demonstrated the presence of some type of dyslipidemia in $99 \%$ of all patients with no significant difference in male and female, with high
TG and low HDL-C levels being the highest prevalence. In addition, higher proportion of patients with NSTEMI had high TG compared to ACS patients presented with either UA or STEMI.

In the current study, the majority of the patients had one or more conventional risk factors for CAD. This indicated a high prevalence of one or more major risk factors for $\mathrm{CAD}$ and ACS like dyslipidemia, hypertension, and diabetes which are similar to other studies. ${ }^{11,12}$ Majority of patients were male $(77.1 \%)$ suggesting that male gender as one of the risk factors for ACS as seen in previous study. ${ }^{13}$

We observe that mean TC, TG, LDL-C and HDL$\mathrm{C}$ among the ACS patients were $196.94 \pm 49.32 \mathrm{mg} /$ $\mathrm{dl}, 201.20 \pm 82.31 \mathrm{mg} / \mathrm{dl}, 120.10 \pm 37.01 \mathrm{mg} / \mathrm{dl}$ and $39.53 \pm 7.13 \mathrm{mg} / \mathrm{dl}$ respectively. Study conducted on adult healthy individuals observed the mean levels of, TC, TG, LDL-C and HDL-C were $173 \pm 26 \mathrm{mg} / \mathrm{dl}$, $98.8 \pm 51 \mathrm{mg} / \mathrm{dl}, 111 \pm 23 \mathrm{mg} / \mathrm{dl}$ and $43.2 \pm 8.7 \mathrm{mg} / \mathrm{dl}$ respectively. ${ }^{14}$ These indicate a significant higher level of TG and LDL-C and lower level of HDL-C in Bangladeshi adults with ACS compared to the healthy adults. Dyslipidemia is an independent 
major risk factor for CAD. Studies have reported a higher prevalence of dyslipidemia among Asians compared to the western population. ${ }^{15} \mathrm{~A}$ combination of low HDL-C and high TG referred to as atherogenic dyslipidemia, have been implicated as important predictors of CAD. ${ }^{16,17}$

In this study, the most commonly observed lipid abnormality was high TG and Low HDL-C. Previous studies on CAD patients also found similar results regarding the presence of high levels of TC, LDL-C, and TG and low levels of HDLC. ${ }^{18,19}$ The lower prevalence of high LDL-C as compared to other fractions is consistent with previous study which showed a higher prevalence of low LDL levels among Asians. ${ }^{15}$ Our study showed low HDL-C levels in a high percentage of patients $(68.8 \%)$ as shown in the previous study which revealed that South Asians had lower HDLC levels than rest of the other population. ${ }^{15}$ These findings may have clinical importance since the prior study in patients with CAD who had a low HDL-C was associated with increased risk for death and MI, even among patients achieved LDL $<70$ $\mathrm{mg} / \mathrm{dl} .^{20}$

The present study identified some gender differences in the distribution of the risk factors. Regarding the relation of ACS type and lipid profile, ACS patients presented with NSTEMI had comparatively higher mean value of TG level than STEMI patients. While there are some similarities between the pathophysiology underlying STEMI and NSTEMI populations, STEMI populations have been found to have an increased pro-inflammatory state and a different serological profile compared to NSTEMI patients. ${ }^{21-23}$

Determining the lipid profile of patients admitted with ACS might allow for an early classification of eventual dyslipidemia and thereby enable the selection of the type and intensity of lipid-lowering therapy. Many of these risk factors, including blood lipids, are modifiable and amenable to treatment.

Limitations: Our study had the limitations of a cross sectional analysis of a group of ACS patients without any control group. Risk-factor identification was based on the information provided by patients or their relatives. Further, our data came from only one hospital; therefore, the results cannot be generalized to other geographical regions. Lipid profile was obtained within the first 24 hours of the event and baseline values were not available for comparison. We did not look at the apolipoprotein measures (Apo B and Apo AI) which are strongly associated with the risk of MI in South Asians.

\section{Conclusion:}

In conclusion, dyslipidemia was a highly prevalent risk factor in patients with ACS. There is a lower prevalence of high LDL-C and high TC and a high prevalence of high TG and lower HDL-C levels among the studied ACS patients.

\section{Recommendations:}

Although Bangladeshi ACS patients are likely to benefit from lowering LDL-C, the threshold for treatment and targets seem to be lower. These thresholds and targets need to be determined by large studies and by our guidelines. Given the higher level of TG and lower levels of HDL-C, approaches to decrease TG and increase the HDL$\mathrm{C}$ may be helpful in our population.

\section{Acknowledgments:}

The authors would like to thank Dr. Israt Ima, Dr. Bushra Abu Bakar, Dr. Tangila Jahan Zishad, and Dr. Farzana Haque for their kind co-operation and support during carrying out the work.

\section{Conflict of Interest - None.}

\section{References:}

1. World Health Organization. Global Health Estimates 2016: Deaths by Cause, Age, Sex, by Country and by Region, 2000 2016. Available from: http://www.who.int/ healthinfo/global_burden_disease/estimate s/en/.

2. Chowdhury M, Haque M, Farhana Z et al. Prevalence of cardiovascular disease among Bangladeshi adult population: a systematic review and meta-analysis of the studies. Vasc Health Risk Manag. 2018; 14: 165181. DOI:10.2147/vhrm. s166111

3. Khanam F, Hossain M, Mistry S, Afsana K, Rahman M. Prevalence and Risk Factors of Cardiovascular Diseases among Bangladeshi Adults: Findings from a Crosssectional Study. J Epidemiol Glob Health. 2019. DOI:10.2991/jegh.k.190531.001.

4. Maron DJ, Rider PM, Grundy SM. Prevention Strategies for Coronary Heart Disease. In: Fuster V, Walsh R, Harrington RA. Eds. Hurst's, the Heart. 13th ed. New York, USA: Mc Graw Hill, 2008: 1235-1244.

5. Lee J, Chang P, Zhang Y, Kizer J, Best L, Howard B. Triglyceride and HDL-C Dyslipidemia and Risks of 
Coronary Heart Disease and Ischemic Stroke by Glycemic Dysregulation Status: The Strong Heart Study. Diabetes Care. 2017; 40(4): 529-537. DOI:10.2337/ dc16-1958

6. Yusuf S, Hawken S, Ônpuu S et al. Effect of potentially modifiable risk factors associated with myocardial infarction in 52 countries (the INTERHEART study): case-control study. The Lancet. 2004; 364(9438): 937952. DOI:10.1016/s0140-6736(04)17018-9

7. Montalescot G, Dallongeville J, Van Belle E et al. STEMI and NSTEMI: are they so different? 1 year outcomes in acute myocardial infarction as defined by the ESC/ACC definition (the OPERA registry). Eur Heart J. 2006; 28(12): 1409-1417. DOI:10.1093/eurheartj/ehm031

8. Parvin D, Baul S, Hossain S, Munshi S, Hadiuzzaman M, Fatema K. Pattern and Prevalence of Dyslipidemia among Patients with Acute Coronary Syndrome Admitted in a Tertiary Level Hospital. Bangladesh Heart Journal. 2019; 34(1): 31-36. DOI:10.3329/bhj. v34i1.41905

9. Findlay I. Definition of acute coronary syndrome. Heart. 2005; 91(7): 857-859. DOI:10.1136/hrt.2004.052795

10. Third Report of the National Cholesterol Education Program (NCEP) Expert Panel on Detection, Evaluation, and Treatment of High Blood Cholesterol in Adults (Adult Treatment Panel III) Final Report. Circulation. 2002; 106(25): 3143-3143. DOI:10.1161/circ.106.25.3143

11. Greenland P. Major Risk Factors as Antecedents of Fatal and Nonfatal Coronary Heart Disease Events. JAMA. 2003; 290(7): 891. DOI:10.1001/ jama.290.7.891

12. Khot UN, Khot MB, Bajzer CT et al. Prevalence of conventional risk factors in patients with coronary heart disease. JAMA. 2003; 290(7): 898-904. DOI:10.1001/ jama.290.7.898

13. Yusufali AM, AlMahmeed W, Tabatabai S, Rao K, Binbrek A. Acute coronary syndrome registry from four large centres in United Arab Emirates (UAE-ACS Registry). Heart Asia. 2010; 2(1): 118-121. DOI:10.1136/ ha.2009.001495
14. Akter T, Khandker E, Polly Z, Khanam F. Lipid profile in an urban healthy adult Bangladeshi population. IMC Journal of Medical Science. 2020; 14(1): 13-17. DOI:10.3329/imcjms. v14i1.47383

15. Karthikeyan G, Teo K, Islam S et al. Lipid Profile, Plasma Apolipoproteins, and Risk of a First Myocardial Infarction Among Asians. J Am Coll Cardiol. 2009; 53(3): 244-253. DOI: 10.1016/j.jacc.2008.09.041

16. Harchaoui K, Visser M, Katelin J, Stroes E, DallingaThie G. Triglycerides and Cardiovascular Risk. Curr Cardiol Rev. 2009; 5(3): 216-222. DOI:10.2174/ 157340309788970315

17. Amarenco P, Labreuche J, Touboul P. High-density lipoprotein-cholesterol and risk of stroke and carotid atherosclerosis: A systematic review. Atherosclerosis. 2008; 196(2): 489-496. DOI: 10.1016/j.atherosclerosis. 2007.07.033

18. Piegas L, Avezum Á, Pereira J et al. Risk factors for myocardial infarction in Brazil. Am Heart J. 2003; 146(2): 331-338. DOI:10.1016/s0002-8703(03)00181-9

19. Avezum A, Piegas LS, Pereira JC. Risk factors associated with acute myocardial infarction in the São Paulo metropolitan region: a developed region in a developing country. Arq Bras Cardiol. 2005; 84(3): 206213. DOI:10.1590/s0066-782x2005000300003

20. Barter P, Gotto A, LaRosa J et al. HDL Cholesterol, Very Low Levels of LDL Cholesterol, and Cardiovascular Events. New England Journal of Medicine. 2007; 357(13): 1301-1310. DOI:10.1056/nejmoa064278

21. Kumar A, Cannon C. Acute Coronary Syndromes: Diagnosis and Management, Part I. Mayo Clin Proc. 2009; 84(10): 917-938. DOI:10.4065/84.10.917

22. Di Stefano R, Di Bello V, Barsotti M et al. Inflammatory markers and cardiac function in acute coronary syndrome: Difference in ST-segment elevation myocardial infarction (STEMI) and in non-STEMI models. Biomedicine \& Pharmacotherapy. 2009; 63(10): 773-780. DOI: 10.1016/j.biopha.2009.06.004

23. Rott D, Leibowitz D. STEMI and NSTEMI are two distinct pathophysiological entities. Eur Heart J. 2007; 28(21): 2685-2685. DOI:10.1093/eurheartj/ehm368 